\title{
Isolation of avian influenza H5N1 virus from vaccinated commercial layer flock in Egypt
}

\author{
Elham F El-Zoghby' ${ }^{1}$, Abdel-Satar Arafa', Walid H Kilany ${ }^{1}$, Mona M Aly ${ }^{1 *}$, Elsayed M Abdelwhab ${ }^{1,2,3}$ \\ and Hafez M Hafez ${ }^{2 *}$
}

\begin{abstract}
Background: Uninterrupted transmission of highly pathogenic avian influenza virus (HPAIV) H5N1 of clade 2.2.1 in Egypt since 2006 resulted in establishment of two main genetic clusters. The 2.2.1/C group where all recent human and majority of backyard origin viruses clustered together, meanwhile the majority of viruses derived from vaccinated poultry in commercial farms grouped in 2.2.1.1 clade.
\end{abstract}

Findings: In the present investigation, an HPAIV H5N1 was isolated from twenty weeks old layers chickens that were vaccinated with a homologous H5N1 vaccine at 1,7 and 16 weeks old. At twenty weeks of age, birds showed cyanosis of comb and wattle, decrease in egg production and up to $27 \%$ mortality. Examined serum samples showed low antibody titer in $\mathrm{HI}$ test ( $\left.\log _{2} 3.2 \pm 4.2\right)$. The hemagglutinin (HA) and neuraminidase (NA) genes of the isolated virus were closely related to viruses in 2.2.1/C group isolated from poultry in live bird market (LBM) and backyards or from infected people. Conspicuous mutations in the HA and NA genes including a deletion within the receptor binding domain in the HA globular head region were observed.

Conclusions: Despite repeated vaccination of layer chickens using a homologous H5N1 vaccine, infection with HPAIV H5N1 resulted in significant morbidity and mortality. In endemic countries like Egypt, rigorous control measures including enforcement of biosecurity, culling of infected birds and constant update of vaccine virus strains are highly required to prevent circulation of HPAIV H5N1 between backyard birds, commercial poultry, LBM and humans.

Keywords: Highly pathogenic avian influenza, H5N1, Egypt, Vaccination failure, Backyards, Live bird markets

\section{Findings \\ Background}

A devastating highly pathogenic avian influenza virus (HPAIV) of H5N1 subtype first emerged in poultry and further transmitted to human in Hong Kong in 1997 [1]. The spread of the H5N1 virus to Europe and Africa was due to a large-scale outbreak of H5N1 infection that occurred in migratory waterfowl in Qinghai Lake (China) in 2005 [2]. To date, ten different genetic clades $(0-9)$ of $\mathrm{H} 5 \mathrm{~N} 1$ virus have been distinguished which further diversified into subclades [3]. The HPAIV H5N1 of clade 2.2.1 has been introduced into Egypt in early 2006 [4] probably via infected wild ducks [5]. Despite control efforts, the virus had become endemic in poultry in

\footnotetext{
*Correspondence: monaaly5@hotmail.com; hafez@vetmed.fu-berlin.de ${ }^{1}$ National Laboratory for Veterinary Quality Control on Poultry Production, Animal Health Research Institute, P.O. Box 246-Dokki, Giza 12618, Egypt Full list of author information is available at the end of the article
}

Egypt since 2008 [6]. Egypt embarked mainly on inactivated $\mathrm{H} 5 \mathrm{~N} 1$ and $\mathrm{H} 5 \mathrm{~N} 2$ vaccines to limit the spread of $\mathrm{H} 5 \mathrm{~N} 1$ virus and minimize its socioeconomic impacts [7]. However, circulation of the HPAIV H5N1 in different poultry species (chickens, ducks, turkeys, etc.), in addition to donkeys and possibly pigs was reported [8-10]. Moreover, out of 168 infected human in Egypt, 60 cases were fatal until July 27, 2012 [11].

In Egypt, H5N1 isolated from humans and a large group of viruses isolated from backyard ducks and chickens clustered in a distinct genetic group designated "2.2.1/C" [12], meanwhile, majority of viruses derived from vaccinated poultry in commercial farms were found in newly named 2.2.1.1 clade [3,13]. A virus belonging to 2.2.1/C group has been also isolated from donkeys in Egypt [8]. Those 2.2.1/C viruses harbor conspicuous mutations in the HA and NA proteins, were thought to be responsible for decreasing virulence in

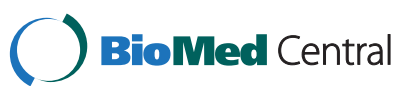


mammals as a step towards adaptation to the human population $[14,15]$. On the contrary, viruses cluster in clade 2.2.1.1, also known as variant 2.2.1 viruses, had extensive amino acids substitutions in or adjacent to the immunogenic epitopes at the proximal globular head region of the HA protein which could enable continuous circulation of the virus in and among commercial poultry despite large scale vaccination campaigns $[16,17]$. Regular nationwide active, passive and targeted surveillance revealed that HPAV H5N1 is perpetuated in many commercial farms, backyards and live bird markets (LBM) $[4,7,9,16,18]$. Culling of infected birds occurs infrequently in Egypt [6].

Backyard birds and commercial poultry are kept in very close contact with humans due to integration of both farms and houses in the same buildings. Employees in commercial farms usually maintain their own household birds. Furthermore, selling of remaining feed, utensils and equipment from commercial farms to the rural family poultry often occurs in Egypt. Backyard chickens, ducks and geese are mostly reared together and roam freely in the vicinity of the house in close contact with human, particularly children. More than $70 \%$ of the Egyptian poultry production from commercial or backyard sectors is marketed through LBM [6]. All H5N1 infected human cases, except three cases, were linked to direct contact of human with sick or apparently healthy birds in backyards and/or LBM [19].

Here we describe the isolation and molecular characterization of an HPAI H5N1 virus isolated from twenty weeks old chicken layer flock, which was vaccinated three times with a commercial inactivated $\mathrm{H} 5 \mathrm{~N} 1$ vaccine.

\section{Methodology}

A commercial chicken farm with 23,699 Hisex-brown layers kept in cages; chickens were vaccinated three times at weeks 1,7 , and 16 with a commercial inactivated $\mathrm{H} 5 \mathrm{~N} 1$ vaccine seeded by A/Goose/Guangdong/1/ 1996/H5N1 (Re-1 YEBIO, Harbin, China). Vaccination of birds was conducted by the owner as part of usual practice. Ten tracheal swabs and ten cloacal swabs were collected randomly at day 7 after onset of clinical signs. At the same time, ten serum samples were collected for further laboratory investigation. Ten swabs were pooled according to Manual of Diagnostic Tests and Vaccines for Terrestrial Animals [20]. No experimental research was conducted in this study and the birds were handled according to the standard guidelines [20]. Samples were collected during the routine nationwide influenza surveillance program after the ministerial decree number 221/2006 in charge the National Laboratory for Veterinary Quality Control on Poultry Production (NLQP) for official diagnosis and surveillance of AIV in Egypt.
Virus isolation trials were carried out in 10-day-old SPF hatching eggs via allantoic sac inoculation [20]. The virus titer was estimated by mean egg-infective dose $\left(\mathrm{EID}_{50} / 0.1 \mathrm{~mL}\right)$ according to Reed and Muench [21]. For detection of avian influenza $\mathrm{H} 5$-specific antibodies in the serum samples; hemagglutination inhibition (HI) test was performed in V-bottom; 96-well microtiter plates with four hemagglutinating units (4HAU) of the indicated homologous A/Goose/Guangdong/1/1996 H5N1 antigen, supplied by the vaccine-producing company (YEBIO, Harbin, China) and 1\% of chicken erythrocytes according to the standard protocol [20]. Results were interpreted as the reciprocal of the last well that showed complete inhibition of the hemagglutination activity of the used $\mathrm{H} 5$ antigen.

Viral RNA from fluid of pooled swabs was extracted using a MagNA Pure LC Total Nucleic Acid Extraction kit following manufacturer's instructions and MagNA Pure LC instrument (Roche, Mannheim, Germany). The RT-qPCR reaction was done using one step Real-Time PCR Kit (Qiagen, Valencia, CA.) as recommended by the manufacturer. Partial matrix (M) gene segment of AIV from viral RNA was amplified according to Spackman et al. [22] using forward primer 5'-AGA TGA GTC TTC TAA CCG AGG TCG-3', reverse primer $5^{\prime}$-TGC AAA AAC ATC TTC AAG TCT CTG-3/and probe $5^{\prime}$ FAMTCA GGC CCC CTC AAA GCC GA-TAMRA-3'. The RT-qPCR reaction was done in Stratagene MX3005P real time PCR machine (Stratagene, Agilent Technologies, Santa Clara, CA). Thereafter, H5 and N1 genes were amplified using generic avian influenza virus H5N1 Real Time RT-PCR RT3 Kits (Roche, Mannheim, Germany) according to the manufacturer guidelines in LightCycler ${ }^{\circledR}$ 2.0 machine.

Amplification of the open reading frame of the HA and NA gene segments was conducted as previously described [16]. The full coding sequences of the HA and NA genes of the isolated virus were conducted using BigDye Terminator v3.1 Cycle Sequencing Kit on an automatic sequencer (ABI-3130; Applied Biosystems, Foster City, CA). The produced sequences were aligned with BioEdit version 7.0.9.0 [23]. Amino acid sequence was deduced and a BLASTN search was performed to identify the query sequence and to find similar sequences. Phylogenetic trees of the obtained $\mathrm{H} 5$ and $\mathrm{N} 1$ genes and other relevant H5N1 genes retrieved from the GenBank data base were generated using the neighbor-joining method with 1000 bootstrap replicates and the evolutionary distances were computed using the Maximum Composite Likelihood method implemented in MEGA5 [24]. Trees were edited for publication using Inkscape software 0.48.1 as shown in Figure 1. Prediction of N-linked glycosylation sites was done by the NetNGlyc 1.0 Server that examines the sequence context of $\mathrm{N}-\mathrm{X}-\mathrm{S} / \mathrm{T}$ sequons [25]. 


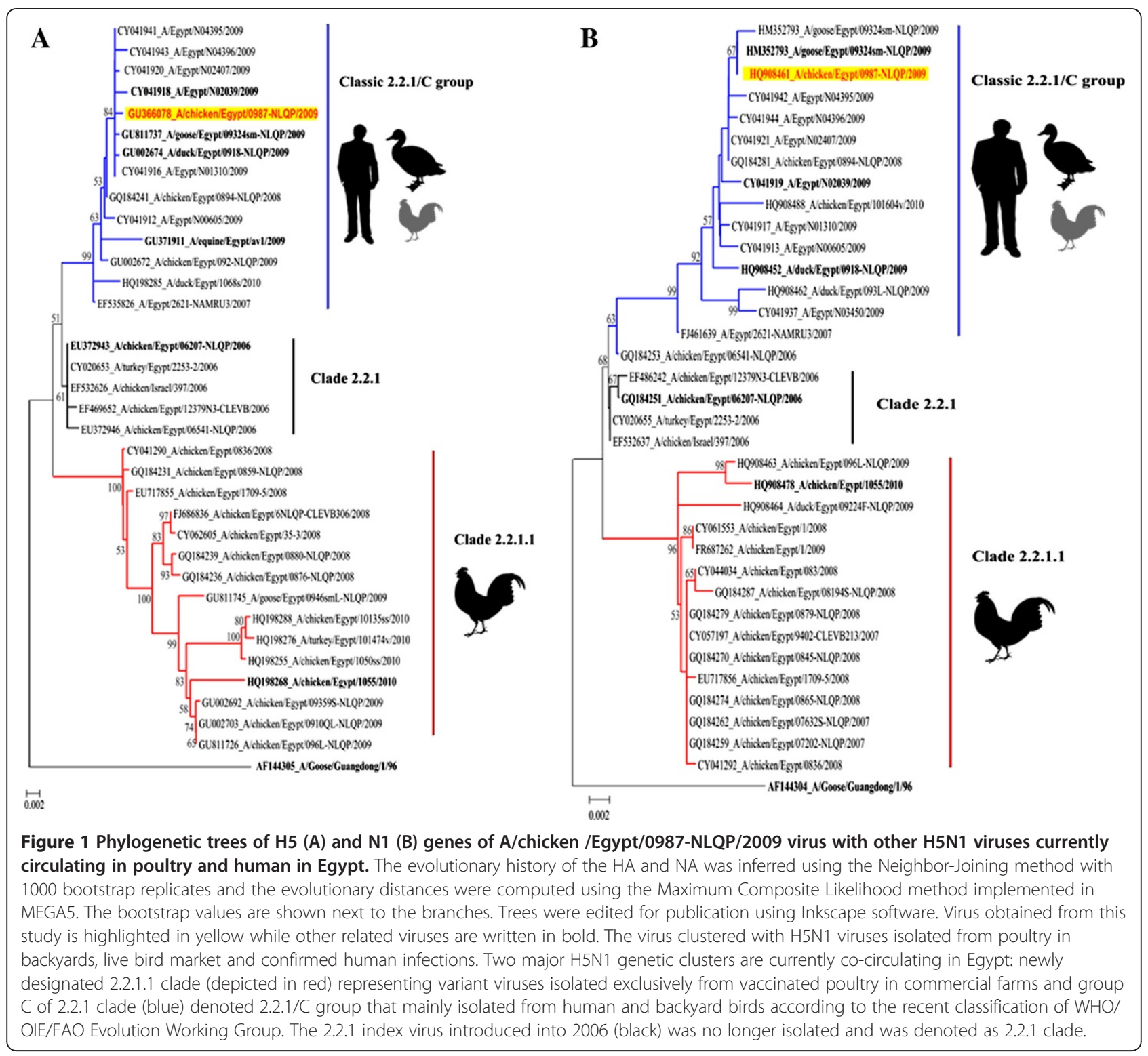

The virus isolated in this study was designated as A/ chicken/Egypt/0987-NLQP/2009(H5N1) and referred to as "Layer/0987". Identity matrix of the isolated virus with other six H5N1 viruses was done: (1) A/goose/ Egypt/09324sm-NLQP/2009 [GenBank: GU811737 and HM352793 for the HA and NA genes, respectively] isolated from geese in live bird market (LBM) in the same region and referred to as LBM/Gs. (2) A/duck/ Egypt/0918-NLQP/2009 [GenBank: GU002674 and HQ908452] isolated from backyard birds referred to as BY/Dk. (3) A/Egypt/N02039/2009 [GenBank: CY041918 and CY041919] was detected from 32 months old boy few days before the incidence of the current outbreak in commercial-layer flock from the same village (case number 57 in the WHO [26]) and referred to as Human/N02039. Those three viruses belong to the
2.2.1/C group. (4) A/chicken/Egypt/06207-NLQP/2006 [GenBank: EU372943 and GQ184251] was isolated in February 2006 and referred to as Index/2006. (5) A/ chicken/Egypt/1055/2010 [GenBank: HQ198268 and HQ908478] a representative virus of the 2.2.1.1 variant clade that was isolated from vaccinated chickens and referred to as Variant/1055. (6) Layer chickens in this study were vaccinated by a commercial vaccine modified by reverse genetic where monobasic-HA and NA genes originated from H5N1 A/Goose/Guangdong/1/96 [GenBank: AF144305 and AF144304] referred to as GsGd/96. The latter was considered to be the parent virus of clade 2.2 [27]. Numbering of amino acid residues of the HA (H5 numbering after removal of the signal peptide) and NA proteins were done in comparison to $\mathrm{GsGd} / 96$ as standard (N1 numbering). 
Tertiary structures of H5 and N1 glycoprotein monomers were generated as PDB using 3D-JIGSAW from Index/2006 virus [28]. Location of amino acid substitutions was imposed on the HA and NA proteins using RasTop software version 2.7.1 [29] and further edited by Inkscape.

\section{Results}

At twenty weeks of age, some birds showed cyanosis of comb and wattles, hemorrhages on the shank and a total mortality estimated to be $27 \%$. In addition, there was a drop in egg production (20\%) and an increase of the number of misshaped eggs (depigmentation, soft eggshell, shell-less and rough eggs). The course of the disease took more than 21 days from onset of clinical illness until depopulation of the flock.

After inoculation of embryonated chicken eggs with tracheal and cloacal swabs media, all embryos died within 48 hours post inoculation. Hemagglutination activity in the harvested allantoin fluid was determined. The isolated virus was confirmed to be an H5N1 virus by partial amplifications of the M, HA and NA genes of avian influenza viruses using specific real-time reverse transcription- polymerase chain reaction (RT-qPCR). The median egg infectious dose was $7.2 \mathrm{EID}_{50} / 0.1 \mathrm{~mL}$.
Serum samples collected at 7 days after the onset of clinical signs had mean HI titer of $3.2 \log _{2}$ (standard deviation $\pm \quad 4.3 \quad \log _{2}$ ) using homologous A/Goose/ Guangdong/1/1996 H5N1 antigen, supplied by the vaccine-producing company (YEBIO, Harbin, China).

The full coding $\mathrm{H} 5$ and $\mathrm{N} 1$ gene sequences generated in this study were submitted to GenBank under accession numbers GU366078 and HQ908461 for the HA and NA genes, respectively. A/chicken/Egypt/0987NLQP/2009(H5N1) isolated in this study had 99.76\% and $99.65 \% \mathrm{HA}$ and $99.85 \%$ and $99.78 \%$ NA nucleotides and amino acids identity, respectively with an H5N1 virus isolated from LBM from the same village as shown in Table 1. A/chicken/Egypt/0987-NLQP/2009 had 99.82\% and $99.65 \% \mathrm{HA}$ and $99.64 \%$ and $99.49 \%$ NA nucleotides and amino acids identity, respectively with an $\mathrm{H} 5 \mathrm{~N} 1$ virus isolated from backyard birds in addition to $99.77 \%$ and $99.47 \% \mathrm{HA}$ and $99.55 \%$ and $99.55 \% \mathrm{NA}$ nucleotides and amino acids identity, respectively with an $\mathrm{H} 5 \mathrm{~N} 1$ virus isolated from 32 months old boy from the same village. However, the virus isolated in this study had nucleotides and amino acids identities of 94.28\% and $94.53 \%$ for the $\mathrm{HA}$ and $93.1 \%$ and $92.04 \%$ for the NA with the vaccine strain (GsGd/96), respectively as shown in (Table 1). Both HA and NA genes

Table 1 Percentage identity of the hemagglutinin and neuraminidase sequences of A/chicken/Egypt/0987-NLQP/2009 in relation to other Egyptian $\mathrm{H} 5 \mathrm{~N} 1$ viruses and vaccine strain

\begin{tabular}{|c|c|c|c|c|c|c|c|}
\hline Hemagglutinin & 'Layer/0987 & ${ }^{2}$ LBM/Gs & ${ }^{3} \mathrm{BY} / \mathrm{Dk}$ & ${ }^{4}$ Human/N02039 & ${ }^{5}$ Index/2006 & ${ }^{6}$ Variant/1055 & ${ }^{7} \mathrm{GsGd} / 96$ \\
\hline Layer/0987 & & 99.77 & 99.83 & 99.77 & 98.90 & 96.19 & 94.28 \\
\hline LBM/Gs & 99.65 & & 99.94 & 99.88 & 98.96 & 96.19 & 94.46 \\
\hline BY/Dk & 99.65 & 100.00 & & 99.94 & 99.02 & 96.13 & 94.52 \\
\hline Human/N02039 & 99.47 & 99.82 & 99.82 & & 98.96 & 96.25 & 94.46 \\
\hline Index/2006 & 98.94 & 99.29 & 99.29 & 99.12 & & 96.88 & 96.02 \\
\hline Variant/1055 & 94.89 & 95.24 & 95.24 & 95.06 & 95.59 & & 92.96 \\
\hline GsGd/96 & 94.53 & 93.47 & 94.71 & 94.53 & 95.41 & 91.71 & \\
\hline Neuraminidase & Layer/0987 & LBM/Gs & $\mathrm{BY} / \mathrm{Dk}$ & Human/N02039 & Index/2006 & Variant/1055 & GsGd/96 \\
\hline Layer/0987 & & 99.85 & 99.64 & 99.55 & 98.58 & 97.30 & 93.01 \\
\hline LBM/Gs & 99.78 & & 99.75 & 99.78 & 98.73 & 97.43 & 91.54 \\
\hline BY/Dk & 99.49 & 99.58 & & 99.49 & 98.56 & 97.20 & 90.59 \\
\hline Human/N02039 & 99.55 & 99.70 & 99.41 & & 98.74 & 97.43 & 91.63 \\
\hline Index/2006 & 98.88 & 99.10 & 98.98 & 98.89 & & 98.49 & 92.62 \\
\hline Variant/1055 & 97.96 & 98.19 & 97.96 & 97.96 & 99.09 & & 91.76 \\
\hline GsGd/96 & 92.04 & 92.26 & 91.35 & 92.04 & 93.18 & 92.19 & \\
\hline
\end{tabular}

Percentage identity of nucleotide (above the diagonal) and amino acid (below the diagonal).

${ }^{1}$ The virus isolated in this study was designated as A/chicken/Egypt/0987-NLQP/2009 under GenBank accession numbers GU366078 and HQ908461 for the HA and NA genes, respectively.

${ }^{2}$ A/goose/Egypt/09324sm-NLQP/2009 [GenBank: GU811737 and HM352793] isolated from geese in live bird market (LBM) in the same region.

${ }^{3}$ A/duck/Egypt/0918-NLQP/2009 [GenBank: GU002674 and HQ908452] isolated from backyard birds.

${ }^{4}$ A/Egypt/N02039/2009 [GenBank: CY041918 and CY041919] isolated from 32 months old boy from the same village.

${ }^{5}$ A/chicken/Egypt/06207-NLQP/2006 [GenBank: EU372943 and GQ184251] was isolated in February 2006 and represents the index 2.2 .1 Egyptian viruses.

${ }^{6} \mathrm{~A} /$ chicken/Egypt/1055/2010 [GenBank: HQ198268 and HQ908478] variant 2.2.1.1 virus isolated from vaccinated chickens in a commercial farm.

${ }^{7}$ A/Goose/Guangdong/1/96 [GenBank: AF144305 and AF144304] vaccine strain used in vaccination of the current commercial layer flock. 
clustered with $2.2 .1 / \mathrm{C}$ group but not with viruses isolated from vaccinated commercial poultry in 2.2.1.1 clade (Figure 1).

The proteolytic cleavage site of the HA had polybasic amino acid motif "ERRRKKR/GLF", typical for HPAIV of clade 2.2. A deletion within the receptor binding site at position 129S (H5 numbering) and additional four amino acid substitutions namely; D43N, S120N, I151T and S320G of viral $\mathrm{H} 5$ protein in comparison to $\mathrm{H} 5 \mathrm{~N} 1$ virus introduced into Egypt in 2006 (Index/2006) were found. All mutations located in the HA1 on the globular head domain (Figure 2). In addition, 14 synonymous mutations were also found. Seven potential glycosylation sites (residues 11, 23, 165, 193, 286, 484 and 543) in the HA protein were predicted. De-glycosylation (loss of asparagine and existence of aspartic acid instead) of amino acid residue 154 was observed.

The NA of A/chicken/Egypt/0987-NLQP/2009 has a deletion of 20 amino acids in the stalk region (49-68; $\mathrm{N} 1$ numbering) in comparison to GsGd/96. Furthermore, in comparison to $\mathrm{H} 5 \mathrm{~N} 1$ virus introduced into Egypt in 2006, A/chicken/Egypt/0987-NLQP/2009 had five amino acid substitutions in the NA protein namely; A46D, N200D, L224M, S339V, and S450G and 14 synonymous mutations in the NA gene. There was no molecular marker of neuraminidase inhibitor resistance. The NA protein had three predicted potential glycosylation sites; residues 68, 126 and 215. On the contrary, GsGd/96 virus had additional four potential glycosylation sites that located in the deleted stalk region of A/chicken/Egypt/0987-NLQP/2009.

\section{Discussion}

Twenty weeks old layer chickens flock vaccinated three times with inactivated $\mathrm{H} 5 \mathrm{~N} 1$ vaccine suffered from respiratory distress and some birds had signs commonly seen in poultry infected with HPAIV. HPAIV H5N1 was isolated from tracheal and cloacal swabs media collected after onset of clinical signs during regular national surveillance. Full H5 and N1 coding gene sequences showed a close genetic relationship between the obtained virus and viruses of LBM, backyards and human origins. Due to insufficiency of epidemiological data, the source of this infection through either LBM, backyard birds or from humans cannot be deduced.

Despite repeated vaccination using a homologous H5N1 vaccine, the chickens exhibited observable distress and mortality. This suggests updated poultry vaccine may be necessary in endemic areas like Egypt. Tian et al., [30] found that the $\mathrm{HI}$ titer of $>4 \log _{2}$ indicated sufficient protection of vaccinated chickens against HPAIV H5N1 infection. In this study, anti-H5 antibody titer was low with variable individual titers $\left(3.2 \pm 4.3 \log _{2}\right)$ after three successive vaccinations of Hisex brown-layers. Recent
A

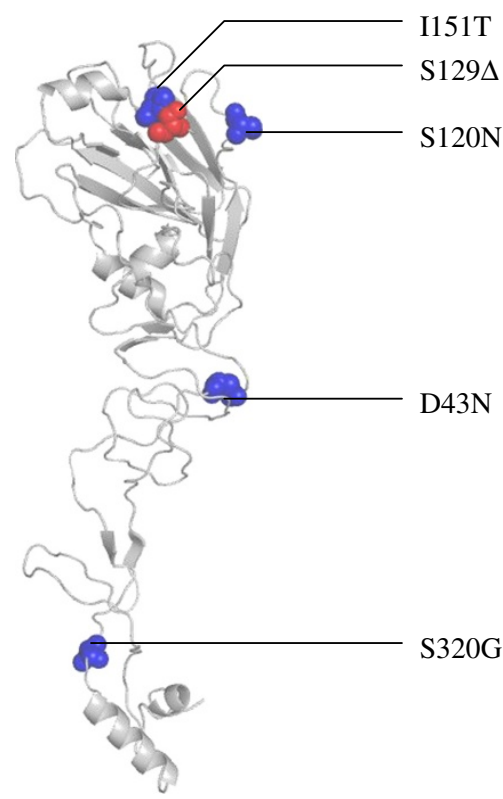

B

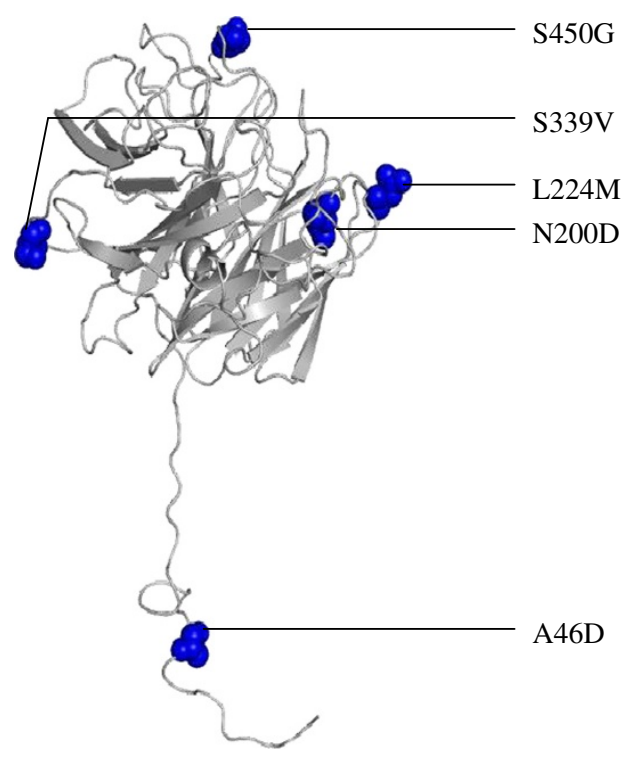

Figure 2 Predicted location of amino acid substitutions found in the isolated virus on the tertiary structure of HA H5 (A) and N1 NA (B) monomers. Shown are the substitutions in D43N, S120N, 1151T and S320G in the HA and A46D, N200D, L224M, S339V and S450G in the NA proteins. Substitutions have been imposed upon the tertiary structure of A/chicken/Egypt/06207-NLQP/2006(H5N1) (index virus of clade 2.2.1 introduced into Egypt in early 2006). Protein modeling was generated by JIGSAW [28] and edited by RasTop version 2.7.1 and further edited by Inkscape. 
experimental studies showed that specific-pathogen-free (SPF) chickens vaccinated with this inactivated $\mathrm{H} 5 \mathrm{~N} 1$ vaccine evoked high $\mathrm{HI}$ titer $\left(7.0 \pm 0.8 \log _{2}\right)$ and were protected against challenge with an Egyptian H5N1 virus belonged to the 2.2.1/C group [31]. Therefore, we assume that improper administration, mishandling and inappropriate storage of the vaccine [7] or suppression of the immune system (i.e.: due to chicken anemia virus infection or ingestion of mycotoxins) [32] could be responsible for such weak immune response and subsequently lack of protection. Moreover, the ability of inactivated $\mathrm{H} 5 \mathrm{~N} 1$ vaccine to evoke effective immune response in $\mathrm{Hi}-$ Sex brown layers remains to be investigated. Taken together, vaccination with regularly updated $\mathrm{H} 5 \mathrm{~N} 1$ vaccines to protect poultry against the evolving $\mathrm{H} 5 \mathrm{~N} 1$ virus in Egypt is highly recommended.

The high level of genetic identity of A/chicken/Egypt/ 0987-NLQP/2009 to viruses in LBM markets and backyard birds suggests a direct transmission link which is not uncommon scenario in Egypt. On the other hand, close genetic relationship between A/chicken/Egypt/ 0987-NLQP/2009 and H5N1 virus isolated from 32 months old boy from the same village could be explained by existence of a common source of infection; most probably backyard birds and/or LBM [7,9]. However, another possible source of infection could be human-to-chicken transmission which instantly could neither be excluded nor confirmed. Subclinical infections of human with H5N1 virus probably due to poultry-to-human, limited human-to-human transmission or environmental source (s) have been reported in China, Cambodia, Vietnam, Thailand and Turkey [33-37]. It is worth pointing out that subclinical infections of apparently healthy pigs and donkeys with HPAIV H5N1 have been reported in Egypt $[8,10]$. Unfortunately there is a paucity of information on subclinical spread among people in Egypt, particularly those in close contact to infected backyard birds or shared in culling of infected commercial farms. However, since late 2008, symptomless cases infected with mild virulent H5N1 in Egypt have raised concern that the virus might be adapted to Egyptians without getting sick [38].

It is well known that affinity of $\mathrm{H} 5 \mathrm{~N} 1$ virus to aviantype $\alpha 2-3$ and mammalian-like $\alpha 2-6$ linked sialic acid receptors seems to be governed by a number of residues in the HA protein including serine at position 129 which is a part of the receptor binding domain (RBD) [39]. It has been found that the Egyptian H5N1 viruses had a potential to use mammalian receptors resembling seasonal H1N1 virus [40]. Deletion of RBD 129S found in A/chicken/Egypt/0987-NLQP/2009 (Figure 2) existed also in all recent isolates of human and backyard origins in Egypt but had neither been reported from the parent GsGd/96 virus [27] nor from Index/2006, the virus originally introduced into Egypt in 2006 . Intriguingly, virus isolated from donkeys belonged to the same 2.2.1/C sublineage (Figure 1). Recently, deletion of RBD 129S combined with I151T in this unique Egyptian genetic group increased affinity of the Egyptian viruses to mammalian receptors and retained its avian receptor specificity [15]. Mutation in this residue was associated with a less virulent $\mathrm{H} 5 \mathrm{~N} 1$ phenotype causing milder or asymptomatic courses of infection and increased transmissibility in mice [41]. Interestingly, other significant substitutions such as Q192R, G222L and Q224S associated with adjustment of the virus from avian to mammalian receptors [42] were not observed in any Egyptian H5 gene sequences, including A/chicken/Egypt/0987-NLQP/2009 [13].

It is well known that $\mathrm{N}$-linked glycosylation of the HA of influenza A viruses can affect receptor binding preferences or mask antigenic regions [41]. A/chicken/Egypt/ 0987-NLQP/2009 like other recent Egyptian H5N1 viruses of human and backyard origin, lost the potential glycosylation site at residue 154 (near the RBD) [13]. This phenotype was associated with (1) increase the affinity of $\mathrm{H} 5$ viruses to $\alpha 2-6$ residues [43], (2) increased transmissibility in guinea pigs and decreased fatality and systemic spread in mice [44]. Taken together, these clues could support the possible scenario of human-to-poultry transmission in Egypt. Therefore, infected human (farm workers, dealers, visitors, etc.) in Egypt should be considered a possible source of infection not only mechanical but also as a biological vector. Moreover, targeted surveillance to identify subclinical infection of human in Egypt should be taken in consideration to avoid a sudden emergence of pandemic virus. On the other hand, residue A46 is located in the NA stalk region while the others are positioned at the surface of the NA monomer (Figure 2). None of NA mutations has a known biological function except $319 \mathrm{~S}$ which is a part of an immunogenic epitope (C) (56). A similar deletion in human H1N1 virus brought with it compensatory changes in the NA to facilitate viral entry and release and a similar mechanism may be acting on the 2.2.1/C viruses of human origin in Egypt [45]. Recently, isolation of H9N2 has been isolated from poultry in Egypt and possible reassortment is expected [46-48].

In conclusion, circulation of HPAIV H5N1 in vaccinated birds continues to devastate the poultry industry in Egypt. Birds in backyards and LBM remain the main potential source of H5N1 infection to both commercial poultry and humans in Egypt. Targeted surveillance to elucidate the spread of HPAIV H5N1 among commercial poultry workers and/or householders should be considered.

\section{Abbreviations}

AIV: Avian influenza virus; D: Aspartic acid; EID: Egg-infective dose; HA: Hemagglutinin; HI: Hemagglutinin inhibition; HPAl: Highly pathogenic avian influenza; I: Isoleucine; G: Glycine; LBM: Live birds markets; 
N: Asparagine; NLQP: National laboratory for quality control on poultry production; OIE: World organization of animal health; RBD: Receptor binding domain; RT-qPCR: Real-time reverse transcription polymerase chain reaction SPF: Specific pathogen free; S: Serine; T: Threonine.

\section{Competing interests}

The authors declare that they have no competing interests.

\section{Authors' contributions}

EFE carried out sample collection and examination and helped to draft the manuscript. AA carried out the sequence of the isolated virus. WHK participated in virus isolation and/or serological examination. EMA did sequence and phylogenetic analyses and helped to draft the manuscript. MMA and HMH conceived and coordinated the study and helped to draft the manuscript. All authors read and approved the final manuscript.

\section{Acknowledgements}

The authors are grateful to all co-workers and colleagues in the NLQP for their excellent technical support.

\section{Author details}

'National Laboratory for Veterinary Quality Control on Poultry Production, Animal Health Research Institute, P.O. Box 246-Dokki, Giza 12618, Egypt. ${ }^{2}$ Institute of Poultry Diseases, Free University of Berlin, Koenigsweg 63, Berlin 14163, Germany. ${ }^{3}$ Federal Research Institute for Animal Health, Friedrich Loeffler Institute, Institute of Molecular Biology, Suedufer 10, Greifswald 17493, Germany

\section{Received: 27 January 2012 Accepted: 24 October 2012}

Published: 27 November 2012

\section{References}

1. Subbarao K, Klimov A, Katz J, Regnery H, Lim W, Hall H, Perdue M, Swayne D, Bender C, Huang J, et al: Characterization of an avian influenza A (H5N1) virus isolated from a child with a fatal respiratory illness. Science 1998, 279:393-396.

2. Guan Y, Smith GJ, Webby R, Webster RG: Molecular epidemiology of H5N1 avian influenza. Rev Sci Tech 2009, 28:39-47.

3. WHO/OIE/FAO Evolution Working Group: Continued evolution of highly pathogenic avian influenza A (H5N1): updated nomenclature. Influenza Other Respi Viruses 2012, 6:1-5.

4. Aly MM, Arafa A, Hassan MK: Epidemiological findings of outbreaks of disease caused by highly pathogenic H5N1 avian influenza virus in poultry in Egypt during 2006. Avian Dis 2008, 52:269-277.

5. Saad MD, Ahmed LS, Gamal-Eldein MA, Fouda MK, Khalil F, Yingst SL, Parker MA, Montevillel MR: Possible avian influenza (H5N1) from migratory bird, Egypt. Emerg Infect Dis 2007, 13:1120-1121.

6. Abdelwhab EM, Hafez HM: An overview of the epidemic of highly pathogenic $\mathrm{H} 5 \mathrm{~N} 1$ avian influenza virus in Egypt: epidemiology and control challenges. Epidemiol Infect 2011, 139:647-657.

7. Hafez MH, Arafa A, Abdelwhab EM, Selim A, Khoulosy SG, Hassan MK, Aly MM: Avian influenza H5N1 virus infections in vaccinated commercial and backyard poultry in Egypt. Poult Sci 2010, 89:1609-1613.

8. Abdel-Moneim AS, Abdel-Ghany AE, Shany SA: Isolation and characterization of highly pathogenic avian influenza virus subtype H5N1 from donkeys. J Biomed Sci 2010, 17:25.

9. Abdelwhab EM, Selim AA, Arafa A, Galal S, Kilany WH, Hassan MK, Aly MM, Hafez MH: Circulation of avian influenza H5N1 in live bird markets in Egypt. Avian Dis 2010, 54:911-914.

10. El-Sayed A, Awad W, Fayed A, Hamann HP, Zschock M: Avian influenza prevalence in pigs, Egypt. Emerg Infect Dis 2010, 16:726-727.

11. WHO: Cumulative number of confirmed human cases for avian influenza $A$ (H5N1) reported to WHO, 2003-2012. 2012. http://www.who.int/influenza/ human_animal_interface/EN_GIP_20120706CumulativeNumberH5N1 cases. pdf.

12. WHO/OIE/FAO Evolution Working Group: Antigenic and genetic characteristics of influenza $A(H 5 N 1)$ and influenza $A(H 9 N 2)$ viruses for the development of candidate vaccine viruses for pandemic preparedness. 2011. http://www.who.int/influenza/resources/documents/

2011_02_h5_h9_vaccinevirusupdate.pdf.
13. Abdelwhab EM, Arafa AS, Stech J, Grund C, Stech O, Graeber-Gerberding M, Beer M, Hassan MK, Aly MM, Harder TC, Hafez HM: Diversifying evolution of highly pathogenic H5N1 avian influenza virus in Egypt from 2006 to 2011. Virus Genes 2012, 45:14-23.

14. Abdelwhab EM, Hafez HM, Aly MM, Grund C, Harder TC: Increasing prevalence of unique mutation patterns in $\mathrm{H} 5 \mathrm{~N} 1$ avian influenza virus $\mathrm{HA}$ and NA glycoproteins from human infections in Egypt. Sequencing 2010, doi:10.1155/2010/450823.

15. Watanabe Y, Ibrahim MS, Ellakany HF, Kawashita N, Mizuike R, Hiramatsu H, Sriwilaijaroen N, Takagi T, Suzuki Y, Ikuta K: Acquisition of human-type receptor binding specificity by new H5N1 influenza virus sublineages during their emergence in birds in Egypt. PLoS Pathog 2011, 7:e1002068.

16. Arafa A, Suarez DL, Hassan MK, Aly MM: Phylogenetic analysis of hemagglutinin and neuraminidase genes of highly pathogenic avian influenza H5N1 Egyptian strains isolated from 2006 to 2008 indicates heterogeneity with multiple distinct sublineages. Avian Dis 2010, 54:345-349.

17. Cattoli G, Milani A, Temperton N, Zecchin B, Buratin A, Molesti E, Aly MM, Arafa A, Capua I: Antigenic drift in H5N1 avian influenza virus in poultry is driven by mutations in major antigenic sites of the hemagglutinin molecule analogous to those for human influenza virus. J Virol 2011, 85:8718-8724

18. Eladl AE, El-Azm KI, Ismail AE, Ali A, Saif YM, Lee CW: Genetic characterization of highly pathogenic H5N1 avian influenza viruses isolated from poultry farms in Egypt. Virus Genes 2011, 43:272-280.

19. Kandeel A, Manoncourt S, el Abd Kareem E, Mohamed Ahmed AN, El-Refaie S, Essmat H, Tjaden J, de Mattos CC, Earhart KC, Marfin AA, El-Sayed N: Zoonotic transmission of avian influenza virus (H5N1), Egypt, 2006-2009. Emerg Infect Dis 2010, 16:1101-1107.

20. Alexander DJ: Avian influenza.Chapter 2.3.4, Manual of Diagnostic Tests and Vaccines for Terrestrial Animals. Paris, France: World Organisation for Animal Health; 2009. http://www.oie.int/fileadmin/Home/eng/Health_standards/ tahm/2.03.04_Al.pdf.

21. Reed $\amalg$, Muench $\mathrm{H}$ : A simple method of estimating fifty percent endpoints. Am J Hygiene 1938, 27:493-497.

22. Spackman E, Senne DA, Bulaga LL, Myers TJ, Perdue ML, Garber LP, Lohman K, Daum LT, Suarez DL: Development of real-time RT-PCR for the detection of avian influenza virus. Avian Dis 2003, 47:1079-1082.

23. Hall TA: BioEdit: a user-friendly biological sequence alignment editor and analysis program for Windows 95/98/NT. Nucleic Acids Symp Ser 1999, 41:95-98.

24. Tamura K, Peterson D, Peterson N, Stecher G, Nei M, Kumar S: MEGA5: molecular evolutionary genetics analysis using maximum likelihood, evolutionary distance, and maximum parsimony methods. Mol Biol Evol 2011, 28:2731-2739.

25. Gupta R, Brunak S: Prediction of glycosylation across the human proteome and the correlation to protein function. Pac Symp Biocomput 2002, 7:310-322

26. WHO: Avian influenza - situation in Egypt - update 6. 2009 http://www.joint/csr/don/2009_03_10/en/indexhtml.

27. Xu X, Subbarao, Cox NJ, Guo Y: Genetic characterization of the pathogenic influenza A/Goose/Guangdong/1/96 (H5N1) virus: similarity of its hemagglutinin gene to those of H5N1 viruses from the 1997 outbreaks in Hong Kong. Virology 1999, 261:15-19.

28. Contreras-Moreira B, Bates PA: Domain fishing: a first step in protein comparative modelling. Bioinformatics 2002, 18:1141-1142.

29. Porollo AA, Adamczak R, Meller J: POLYVIEW: a flexible visualization tool for structural and functional annotations of proteins. Bioinformatics 2004, 20:2460-2462.

30. Tian G, Zhang S, Li Y, Bu Z, Liu P, Zhou J, Li C, Shi J, Yu K, Chen H: Protective efficacy in chickens, geese and ducks of an H5N1-inactivated vaccine developed by reverse genetics. Virology 2005, 341:153-162.

31. Hassan MK, Kilany WH, Abdelwhab EM, Arafa AS, Selim A, Samy A, Samir M, Le Brun Y, Jobre Y, Aly MM: Distribution of avian influenza H5N1 viral RNA in tissues of Al-vaccinated and unvaccinated contact chickens after experimental infection. Arch Virol 2012, 157:951-959.

32. Hegazy AM, Abdallah FM, El Abd-Samie LK, Nazim AA: The relation between some immunosuppressive agents and widespread nature of highly pathogenic avian influenza (HPAl) post vaccination. Journal of American Science 2011, 7:66-72. 
33. Khuntirat BP, Yoon IK, Blair PJ, Krueger WS, Chittaganpitch M, Putnam SD, Supawat K, Gibbons RV, Pattamadilok S, Sawanpanyalert P, et al: Evidence for subclinical avian influenza virus infections among rural Thai villagers. Clin Infect Dis 2011, 53:e107-e116.

34. Powell TJ, Fox A, Peng Y, Quynh Mai le T, Lien VT, Hang NL, Wang L, Lee LY, Simmons CP, McMichael AJ, et al: Identification of H5N1-specific T-cell responses in a high-risk cohort in vietnam indicates the existence of potential asymptomatic infections. J Infect Dis 2012, 205:20-27.

35. Huo X, Zu R, Qi X, Qin Y, Li L, Tang F, Hu Z, Zhu F: Seroprevalence of avian influenza A (H5N1) virus among poultry workers in Jiangsu Province. China: an observational study. BMC Infect Dis 2012, 12:93.

36. Ceyhan M, Yildirim I, Ferraris O, Bouscambert-Duchamp M, Frobert E, Uyar $\mathrm{N}$, Tezer H, Oner AF, Buzgan T, Torunoglu MA, et al: Serosurveillance study on transmission of H5N1 virus during a 2006 avian influenza epidemic. Epidemiol Infect 2010, 138:1274-1280.

37. Vong S, Ly S, Van Kerkhove MD, Achenbach J, Holl D, Buchy P, Sorn S, Seng $H$, Uyeki TM, Sok T, Katz JM: Risk factors associated with subclinical human infection with avian influenza A (H5N1) virus-Cambodia, 2006. J Infect Dis 2009, 199:1744-1752.

38. Anon: Concerns arise over symptomless Egypt bird flu cases. 2009. http://www.flutrackers.com/forum/showthread.php?t=98884.

39. Durvuri VR, Durvuri B, Cuff WR, Wu GE, Wu J: Role of positive selection pressure on the evolution of H5N1 hemagglutinin. Genomics Proteomics Bioinformatics 2009, 7:47-56.

40. Veljkovic V, Niman HL, Glisic S, Veljkovic N, Perovic V, Muller CP: Identification of hemagglutinin structural domain and polymorphisms which may modulate swine $\mathrm{H} 1 \mathrm{~N} 1$ interactions with human receptor. BMC Struct Biol 2009, 9:62.

41. Kaverin NV, Rudneva IA, Govorkova EA, Timofeeva TA, Shilov AA, Kochergin-Nikitsky KS, Krylov PS, Webster RG: Epitope mapping of the hemagglutinin molecule of a highly pathogenic $\mathrm{H} 5 \mathrm{~N} 1$ influenza virus by using monoclonal antibodies. J Virol 2007, 81:12911-12917.

42. Matrosovich M, Zhou N, Kawaoka Y, Webster R: The surface glycoproteins of $\mathrm{H} 5$ influenza viruses isolated from humans, chickens, and wild aquatic birds have distinguishable properties. J Virol 1999, 73:1146-1155.

43. Smith GJ, Naipospos TS, Nguyen TD, de Jong MD, Vijaykrishna D, Usman TB, Hassan SS, Nguyen TV, Dao TV, Bui NA, et al: Evolution and adaptation of H5N1 influenza virus in avian and human hosts in Indonesia and Vietnam. Virology 2006, 350:258-268.

44. Gao Y, Zhang Y, Shinya K, Deng G, Jiang Y, Li Z, Guan Y, Tian G, Li Y, Shi J, et al: Identification of amino acids in $\mathrm{HA}$ and $\mathrm{PB} 2$ critical for the transmission of H5N1 avian influenza viruses in a mammalian host. PLoS Pathog 2009, 5:e1000709.

45. McDonald NJ, Smith CB, Cox NJ: Antigenic drift in the evolution of H1N1 influenza $A$ viruses resulting from deletion of a single amino acid in the haemagglutinin gene. J Gen Virol 2007, 88:3209-3213.

46. El-Zoghby EF, Arafa AS, Hassan MK, Aly MM, Selim A, Kilany WH, Selim U, Nasef S, Aggor MG, Abdelwhab EM, Hafez HM: Isolation of H9N2 avian influenza virus from bobwhite quail (Colinus virginianus) in Egypt. Arch Virol 2012, 157:1167-1172.

47. Abdel-Moneim AS, Afifi MA, El-Kady MF: Isolation and mutation trend analysis of influenza A virus subtype H9N2 in Egypt. Virol J 2012, 9:173.

48. Arafa AS, Hagag N, Erfan A, Mady W, El-Husseiny M, Adel A, Nasef S: Complete genome characterization of avian influenza virus subtype H9N2 from a commercial quail flock in Egypt. Virus Genes 2012, 45:283-294

doi:10.1186/1743-422X-9-294

Cite this article as: El-Zoghby et al:: Isolation of avian influenza H5N1 virus from vaccinated commercial layer flock in Egypt. Virology Journal 2012 9:294.

\section{Submit your next manuscript to BioMed Central and take full advantage of:}

- Convenient online submission

- Thorough peer review

- No space constraints or color figure charges

- Immediate publication on acceptance

- Inclusion in PubMed, CAS, Scopus and Google Scholar

- Research which is freely available for redistribution

Submit your manuscript at www.biomedcentral.com/submit 